Eur. J. Clin. Chem. Clin. Biochem.

Vol. 31, 1993, pp. 83-90

(C) 1993 Walter de Gruyter \& Co.

Berlin $\cdot$ New York

\title{
Preferential Inhibition of LDL Oxidation by the all-trans Isomer of $\beta$-Carotene in Comparison with 9-cis $\beta$-Carotene
}

\author{
By Alexandra Lavy ${ }^{1}$, A. Ben Amotz ${ }^{2}$ and M. Aviram ${ }^{1}$ \\ 1 Lipid Research Laboratory, Rambam Medical Center and Bruce Rappaport Faculty of Medicine, Technion \\ and the Rappaport Institute for Research in the Medical Sciences, Haifa, Israel \\ 2 The National Institute of Oceanography, Tel Shikmona, Haifa, Israel
}

(Received July 2/September 7, 1992)

Summary: The synthetic all-trans isomer of $\beta$-carotene was recently shown to possess antioxidant properties towards the formation of oxidized low density lipoprotein.

In the present study, the binding of the all-trans and the 9-cis isomers of $\beta$-carotene to plasma lipoproteins was investigated, and the effect of these isomers on the susceptibility of plasma lipoprotein to lipid peroxidation and on macrophage uptake of oxidized LDL were studied. Both the synthetic all-trans isomer of $\beta$-carotene and the natural $\beta$-carotene from the algae Dunaliella Bardawil [which is composed of the all-trans (70\%) and the 9-cis (30\%) isomers], were found to bind similarly to all plasma lipoproteins, following the incubation of $\beta$-carotene with purified lipoproteins or with whole plasma.

Incubation of the $\beta$-carotene isomers with whole plasma, followed by separation of the lipoproteins, revealed substantial carotene binding to very low density lipoprotein (VLDL) and to LDL and limited binding to high density lipoprotein (HDL). Lipid peroxidation of VLDL and LDL were significantly inhibited by $\beta$-carotene.

The synthetic $\beta$-carotene, however, was twice as effective as the Dunaliella $\beta$-carotene in inhibiting LDL lipid peroxidation (following LDL incubation with copper ions). Cellular degradation of oxidized lipoproteins (mediated via the scavenger receptor) was decreased by $40 \%$ and $18 \%$, respectively, when they were prepared by incubation in the presence of synthetic or natural $\beta$-carotene; the control oxidized LDL was prepared in the absence of $\beta$-carotene.

$\beta$-Carotene probably binds to the cholesteryl ester moiety of LDL, and causes changes in the physicochemical properties of the lipoprotein. The synthetic all-trans isomer of $\beta$-carotene, but not the natural $\beta$-carotene, reduced LDL electrophoretic mobility and increased the availability of free amino groups of lysine residues.

We conclude that altough both the all-trans and the 9-cis isomers of $\beta$-carotene can bind in vitro to plasma lipoproteins, they exert different effects of LDL atherogenicity; the all-trans isomer of $\beta$-carotene is more effective in inhibiting the susceptibility of lipoproteins to lipid peroxidation and in reducing the cellular uptake of oxidized LDL by macrophages.

\section{Introduction}

Carotenes, the major precursors of vitamin A (retinol), are synthesized by plants but not by humans. $\beta$-Carotene, the major carotenoid in human plasma, is a symmetrical molecule containing $2 \beta$-ionone rings connected by an hydrocarbon chain, which consists of 18-carbon atoms and contains 11 conjugated double bonds (1). $\beta$-Carotene is absorbed into the blood via the lymphatic system and is transported in the circulation by plasma lipoproteins, mainly low density lipoprotein (LDL) $(2-5)$. $\beta$-Carotene has several different effects, including growth promotion, develop- 
ment of skin and tissues, electron transfer reactions and maintenance of the integrity of cell membranes and cell organelles. Epidemiological and biochemical studies suggest that $\beta$-carotene possesses antiatherogenic, anticancer and antioxidant properties (6-9). Under a physiological oxygen partial pressure, $\beta$ carotene acts as a radical-trapping agent and a chainbreaking antioxidant $(10,11)$. The synthetic all-trans isomer of $\beta$-carotene possesses different properties from the natural 9-cis isomer. The latter accounts for about $30 \%$ of the natural $\beta$-carotene found in plants (the other $70 \%$ is the all-trans isomer) and it occurs in large quantities in the halotolerant algae, Dunaliella $\operatorname{Bardawil}(12,13)$. The 9-cis $\beta$-carotene is more soluble in hydrophobic solvents than the all-trans form, and it is not easily crystalized $(13,14)$. These properties may be responsible for the difference in absorption of the isomers and for the preferable accumulation of the 9-cis isomer in the liver of rats and chicks after feeding natural $\beta$-carotene (13). Dietary supplementation with $\beta$-carotene or vitamin $\mathrm{E}$, as well as in vitro enrichment of plasma with these substances, have been shown to result in their binding to plasma lipoproteins and in lipoprotein resistance to in vitro lipid peroxidation $(6,15-18)$.

Oxidative modification of LDL leads to enhanced macrophage uptake of the modified lipoprotein (19) and to macrophage cholesterol accumulation, which is an early event in atherogenesis (19-21). Since oxidized LDL exists in vivo (22), the oxidation state of the lipoprotein as well as its susceptibility to lipid peroxidation are both important features of its atherogenicity $(23-25)$.

Substances which may affect LDL susceptibility to oxidation include the content of its various fatty acids and antioxidants $(17,18)$, which can also affect the extent of LDL cellular uptake by macrophages (16$21,26,27)$. Studies of the effect of $\beta$-carotene on LDL oxidation and on macrophage uptake of the lipoprotein $(7,17)$ have been reported using only the synthetic all-trans isomer.

The present study was undertaken in order to analyse the in vitro binding properties to plasma lipoproteins of the all-trans and the 9-cis isomers of $\beta$-carotene, to compare their effect on lipoprotein susceptibility to lipid peroxidation, and to analyse their effect on the cellular uptake of the oxidized lipoproteins.

\section{Materials and Methods}

\section{Material}

The synthetic $\beta$-carotene all-trans isomer was obtained from Hoffman La Roche (Basel, Switzerland) and the natural Dunaliella Bardawil $\beta$-carotene was obtained from the National
Institute of Oceanography, Tel Shikmona, Haifa, Israel. $\beta$-Carotene was dissolved in tetrahydrofuran or in hexane, or it was incorporated into phospholipid liposomes. A solution of $\beta$-carotene $(1 \mathrm{~g} / \mathrm{l})$ was added to a dispersion of chromatographically pure egg phosphatidylcholine $(10 \mathrm{~g} / \mathrm{l})$ (Sigma Chemical Co., St. Louis, MO) to give a concentration of $10 \mathrm{mg} / 1 \beta$-carotene (the solvent volume was therefore $1 \%$ of the total incubation volume). This mixture was sonicated at $4{ }^{\circ} \mathrm{C}$ under argon for 20 minutes $(\times 3)$ followed by centrifugation $(1500 \mathrm{~g}, 10$ minutes), and the liposomes were collected by filtration through a $0.45 \mu \mathrm{m}$ filter (28). Since carotenoids are very sensitive to light-induced oxidation, all carotene preparations were kept in covered bottles under nitrogen at $-20^{\circ} \mathrm{C}$. The concentration of the $\beta$-carotene solutions was determined from the UV absorption using an appropriate standard, and the $\beta$-carotene was identified by HPLC. LDL was used at a protein concentration of $1 \mathrm{~g} / \mathrm{l}$. Control incubations (without $\beta$-carotene) always included the appropriate solvent.

\section{Lipoproteins}

Blood was drawn from 25 normolipidaemic males aged $23-30$ years into $\mathrm{Na}_{2}$ EDTA (1 mmol/l) after a 14-hour of fast. Plasma lipoproteins were separated by density gradient ultracentrifugation (29) and dialysed against saline-EDTA. For LDL oxidation, the lipoproteins were diluted in phosphate-buffered saline to a protein concentration of $500 \mathrm{mg} / \mathrm{l}$ and dialysed overnight against phosphate-buffered saline at $4{ }^{\circ} \mathrm{C}$. The lipoproteins were then incubated in the presence of $10 \mu \mathrm{mol} / 1 \mathrm{CuSO}_{4}$ at $37^{\circ} \mathrm{C}$ for 24 hours. Oxidation was terminated by refrigeration and the addition of $0.1 \mathrm{mmol} / \mathrm{l}$ EDTA. The degree of lipoprotein oxidation was determined by analysis of malondialdehyde equivalents using the thiobarbituric acid reactive substances assay, as well as by analysis of the lipoprotein peroxide content $(30,31)$. The presence of reactive amino groups on the LDL apolipoprotein B-100 molecule was estimated with trinitrobenzene sulphonic acid (32).

Lipoprotein (50 $\mu \mathrm{g}$ of protein) was mixed with $1 \mathrm{ml}$ of $40 \mathrm{~g} / \mathrm{l}$ $\mathrm{NaHCO}_{3}, \mathrm{pH} \mathrm{8.4}$, and $50 \mu \mathrm{l}$ of $1 \mathrm{~g} / 1$ trinitrobenzene sulphonic acid. After incubation for 1 hour at $37^{\circ} \mathrm{C}$, the reaction was terminated by the addition of $100 \mu \mathrm{l}$ of $1 \mathrm{~mol} / 1 \mathrm{HCl}$ and $100 \mu \mathrm{l}$ of $100 \mathrm{~g} / \mathrm{l}$ sodium dodecyl sulphate, and the absorbance at 340 $\mathrm{nm}$ was measured. LDL electrophoresis was performed on cellulose acetate in barbital buffer, $\mathrm{pH} 8.6$ (33). Protein content of the lipoproteins was determined by the Folin phenol reagent (34).

The vitamin E content of the lipoproteins was analysed (using $\alpha$-tocopherol diluted in ethanol as an external standard), and the concentration of total carotenoids was determined in the LDL using $\beta$-carotene as a standard. Two $\mathrm{ml}$ of LDL (concentration $1 \mathrm{~g} / \mathrm{l}$ ) were mixed with $2 \mathrm{ml}$ of $100 \mathrm{~g} / \mathrm{l} \mathrm{KOH}$ (in ethanol) and saponified for one hour at $60^{\circ} \mathrm{C}$. This saponification procedure was necessary for phase separation in samples with high lipid concentrations. After cooling, $2 \mathrm{ml}$ of hexane were added and the hexane phase was then separated by centrifugation at $500 \mathrm{~g}$ for 10 minutes. The absorbance of the LDL lipids was scanned from $200 \mathrm{~nm}$ to $700 \mathrm{~nm}$ versus hexane using a flowthrough spectrophotometer (model 8452A Diode Array, Hewlett-Packard, Rockville, MD). The total carotenoid concentration was calculated, using the extinction coefficient (for $1 \%$ solution) of 2550 at $450 \mathrm{~nm}$. The vitamin E content was calculated, using the extinction coefficient of 71 at $292 \mathrm{~nm}$ (13). To measure the $\beta$-carotene isomers, the hexane phase was evaporated to dryness under nitrogen, the residues redissolved in a minimal volume $(200 \mu \mathrm{l})$ of hexane, then injected into a high performance liquid chromatography (HPLC) analyser. A stainless steel column $(25 \times 4.6 \mathrm{~mm}$ i. d. $)$ packed with $\mathrm{C} 18$ reversed phase material of $5 \mu \mathrm{m}$ particle size was used. Elution was performed with methanol : acetonitrile $(9+1$, by vol.), at $1 \mathrm{ml} /$ min. A gradual increase of retention time after about 20 injections of sample was reversed by washing the column with 
methanol: acetonitrile: methylcne chloride $(8+1+1$, by vol.). LDL fatty acid composition was analysed after methylation by gas chromatography (35).

Thin layer chromatography (TLC) of the LDL lipids and $\beta$ carotene was carried out in silica gel plates using a solution of hexane: diethyl ether : acetic acid $(130+40+15$, by vol.). The $\beta$-carotene was visualized directly (and analysed by HPLC), and the LDL lipids were visualized by exposing to iodine vapors.

\section{Macrophage degradation of LDL}

The degradation of oxidized [125]]LDL or $\beta$-carotene-enriched oxidized [ $\left.{ }^{125} \mathrm{I}\right] \mathrm{LDL}$ by the macrophage-like cell line J-774A.1 was measured. Hydrolysis of the lipoprotein protein was assayed in the incubation medium by measurement of trichloroacetic acid-soluble, non iodide radioactivity (36).

Cell-free LDL degradation was minimal and was subtracted from total LDL degradation. The cell layer was washed three times with phosphate-buffered saline then extracted by incubation for $1 \mathrm{~h}$ at room temperature with $0.5 \mathrm{ml}$ of $0.1 \mathrm{~mol} / 1$ $\mathrm{NaOH}$ for measurement of protein (34).

\section{Statistics}

Student's t-test was performed for all statistical analysis. Results represent mean $\pm S$. D.

\section{Results}

Incubation of $\beta$-carotene with isolated lipoproteins or whole plasma

$\beta$-Carotene $(10 \mathrm{mg} / \mathrm{l})$ was incubated with plasma lipoproteins (protein concentration $1 \mathrm{~g} / \mathrm{l}$ ) for 2 hours at $37^{\circ} \mathrm{C}$, followed by separation of the lipoproteins on a Sephadex G-100 minicolumn. Substantial binding of the $\beta$-carotene to VLDL, LDL and HDL was noted (fig. 1). $\beta$-Carotene from Dunaliella (a mixture composed of $30 \% 9$-cis isomer and $70 \%$ of the all-trans isomer) was shown to bind to the lipoproteins and increased the content of $\beta$-carotene in VLDL, LDL and HDL by $121 \%, 38 \%$ and $22 \%$ respectively (fig. 1a).

Incubation with synthetic $\beta$-carotene (all-trans isomer) resulted in an elevation of the $\beta$-carotene content of the lipoprotein by $100 \%, 27 \%$ and $44 \%$ in VLDL, LDL and HDL, respectively, compared with control lipoproteins (preincubated without $\beta$-carotene) (fig. 1a). In parallel, the oxidation rates of VLDL, LDL and HDL (measured as malondialdehyde equivalents), were reduced by the $\beta$-carotene-Dunaliella by $23 \%, 33 \%$ and $32 \%$ respectively (fig. $1 \mathrm{~b}$, \#2 vs. \#1). Synthetic carotene, under similar experimental conditions, showed a much higher inhibition of lipoprotein oxidation than the mixed isomer preparation. Lipoprotein-associated malondialdehyde concentrations were reduced by $52 \%, 50 \%$ and $45 \%$ in VLDL, LDL and HDL, compared with control lipoproteins

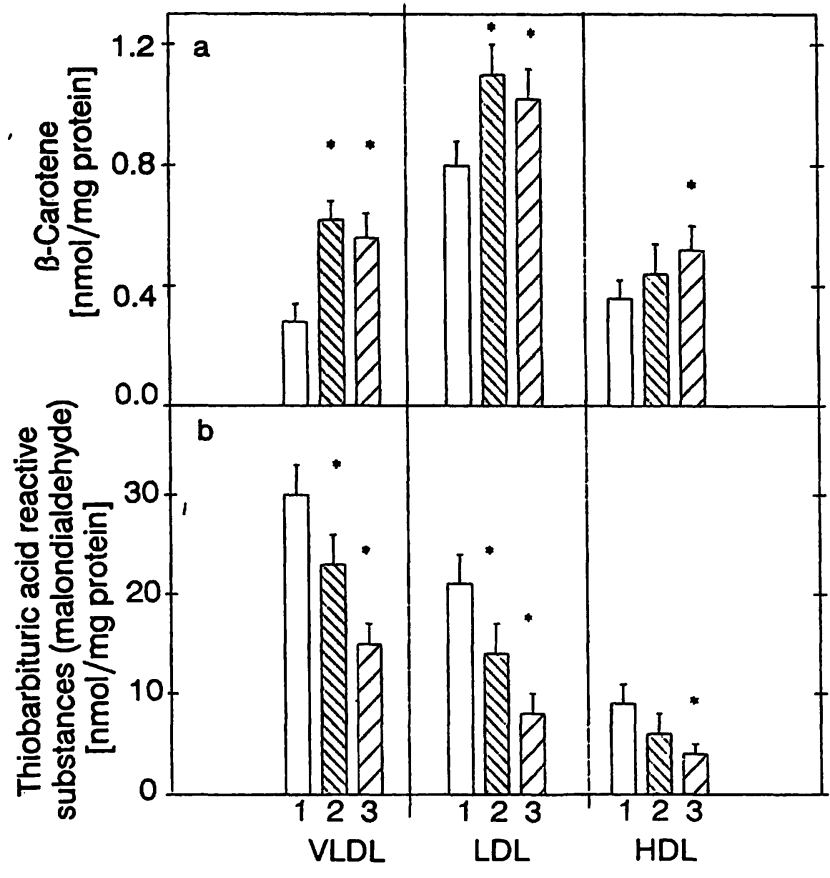

Fig. 1. The binding of synthetic all-trans $\beta$-carotene and the natural $\beta$-carotene from Dunaliella to plasma lipoproteins (a) and their effect on the susceptibility of the lipoproteins to in vitro lipid peroxidation (b).

Plasma lipoproteins (protein: $1 \mathrm{~g} / \mathrm{l}$ ) were incubated for 3 hours at $37^{\circ} \mathrm{C}$ without (control) or with $10 \mathrm{mg} / \mathrm{l}$ of $\beta$-carotene, following by lipoprotein separation on a Sephadex G-100 minicolumn $(2 \times 10 \mathrm{~cm})$. The $\beta$-carotene content of the lipoproteins was determined and lipoprotein susceptibility to lipid peroxidation was measured as described under Methods.

* $\mathrm{p}<0.01$ vs. control $(\mathrm{n}=3)$.

1-Control lipoprotein, 2- $\beta$-carotene-Dunaliella-enriched lipoprotein, 3-synthetic $\beta$-carotene-enriched lipoprotein.

incubated without $\beta$-carotene (fig. $1 \mathrm{~b}, \# 3$ vs. \#1). The fatty acid content and distribution in all lipoproteins was not significantly affected following lipoprotein incubation with $\beta$-carotene (data not shown). We next studied $\beta$-carotene binding to the lipoproteins after 2 hours of incubation of fresh plasma with 10 $\mathrm{mg} / \mathrm{l}$ of $\beta$-carotene. Plasma concentration of $\beta$-carotene was increased from $1.52 \pm 0.12 \mu \mathrm{mol} / \mathrm{l}$ to 4.40 \pm 0.08 or $3.80 \pm 0.06 \mu \mathrm{mol} / \mathrm{l}(\mathrm{n}=4)$, following incubation with $\beta$-carotene - Dunaliella or with the synthetic all-trans isomer, respectively.

Upon separation of the plasma lipoproteins, the content of $\beta$-carotene in VLDL, LDL and HDL was shown to have increased by about $160 \%, 100 \%$, and $30 \%$, respectively, over the control lipoproteins (incubated without $\beta$-carotene). Similar results were obtained with both isomers of $\beta$-carotene (fig. 2).

When the incubation time was increased from 2 hours to 24 hours, the $\beta$-carotene content of plasma lipoproteins was further increased by only $19-29$ percent (data not shown). 


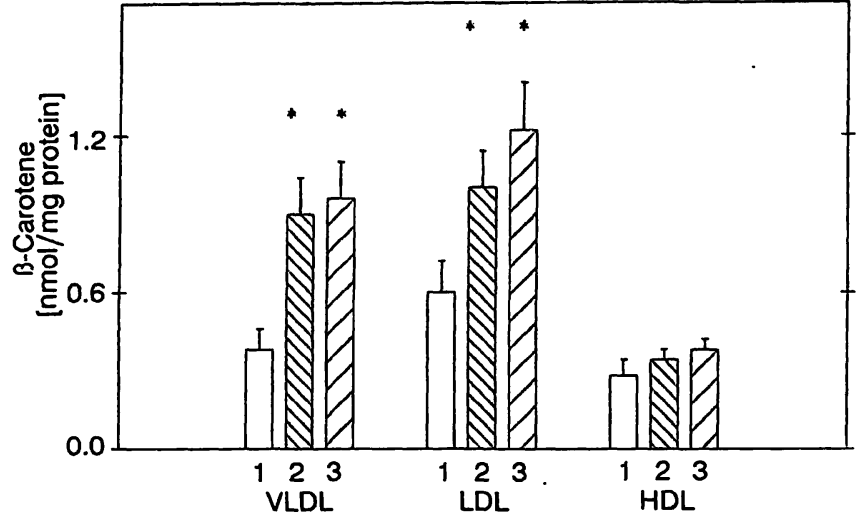

Fig. 2. The binding of $\beta$-carotene isomers to lipoproteins in plasma. Plasma was incubated without (control, \#1) or with $10 \mathrm{mg} / \mathrm{l}$ of $\beta$-carotene from Dunaliella (\#2) or with synthetic $\beta$-carotene (\#3) for 2 hours at $37^{\circ} \mathrm{C}$ prior to the separation of plasma lipoproteins by ultracentrifugation. The $\beta$-carotene content of each lipoprotein was then determined.

${ }^{*} \mathrm{p}<0.01$ vs. control $(\mathrm{n}=3)$.

The extent of lipoprotein oxidation was determined by analysis of the lipoprotein-associated peroxides, by determination of the malondialdehyde equivalents, and by determination of trinitrobenzene sulphonic acid reactivity (which measures free lysine amino residues). In both VLDL and LDL, $\beta$-carotene from Dunaliella reduced the peroxide and malondialdehyde contents and inhibited the reduction in trinitrobenzene sulphonic acid reactivity by $15-31 \%$ in comparison with the control lipoproteins (fig. $3 \mathrm{a}-\mathrm{c}$, \#2 vs. \#1). Synthetic $\beta$-carotene (fig. $3, \# 3$ ) was a stronger inhibitor of lipoprotein oxidation than the $\beta$-carotene from Dunaliella (fig. 3 , \# 3 vs. \#2). This synthetic isomer resulted in a further reduction (by $20-30 \%$ ) of the peroxide and malondialdehyde contents (fig. $3 \mathrm{a}, \mathrm{b}$ ) and an increase $(20-25 \%)$ of trinitrobenzene sulphonic acid reactivity (fig. $3 \mathrm{c}$ ), compared with the effect of $\beta$-carotene from Dunaliella. The HDL fraction, in comparison with VLDL and LDL, showed a much lower oxidation rate, and the effect of $\beta$-carotene on HDL oxidation was minimal (fig. $3 \mathrm{a}-\mathrm{c}$ ). The greater inhibition of LDL oxidation by the synthetic, all-trans isomer than by the natural $\beta$-carotene from Dunaliella was further studied. When natural $\beta$-carotene from Daniella enriched with the 9cis isomer (45\% 9-cis compared with $30 \%$ in the original $\beta$-carotene from Dunaliella) was used, there was only a minimal inhibitory effect on copper ionmediated LDL oxidation (malondialdehyde $31 \pm 5$ vs. $24 \pm 4 \mathrm{nmol} / \mathrm{mg}$ protein in LDL treated with the 9-cis-enriched carotene, compared with the $\beta$-carotene from Dunaliella; the oxidation rate of control LDL (with no added $\beta$-carotene) corresponded to a malondialdehyde content of $35 \pm 4 \mathrm{nmol} / \mathrm{mg}$ protein).
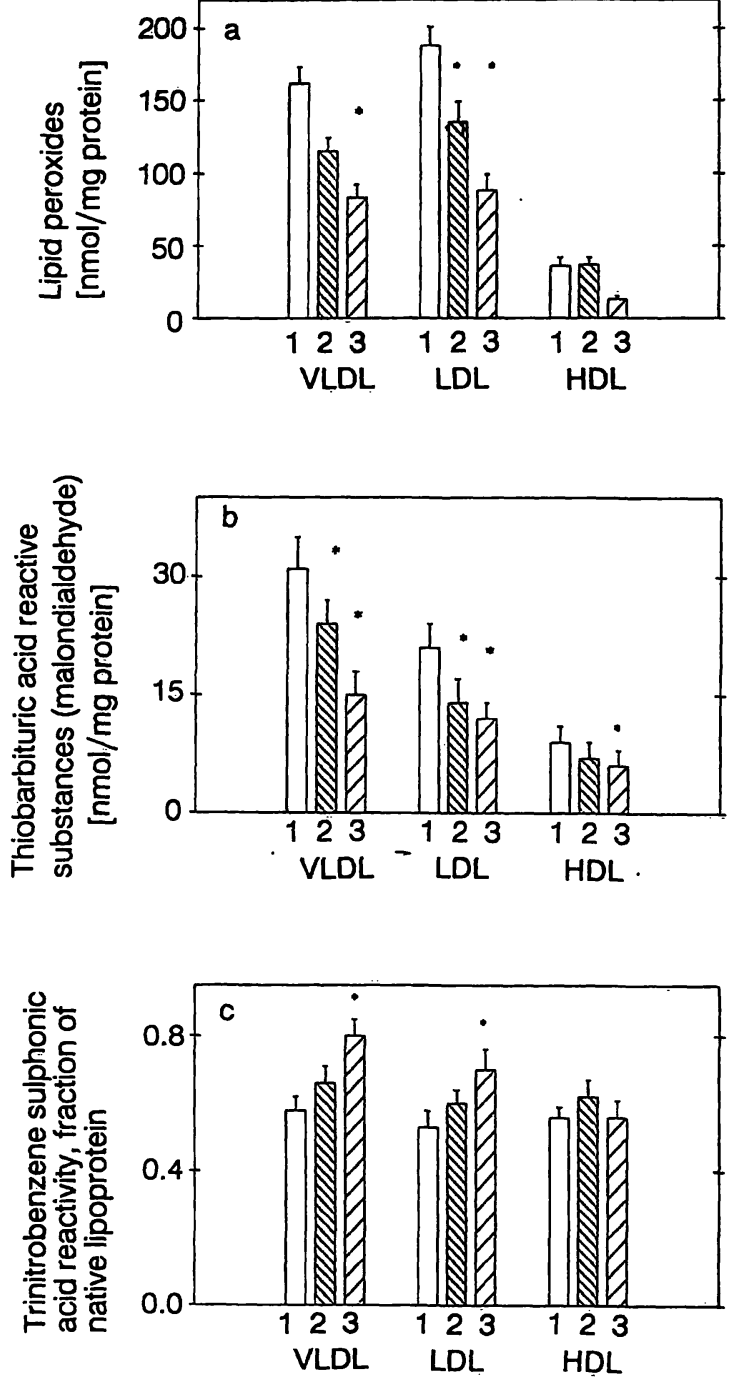

Fig. 3. Effect of enrichment with $\beta$-carotene from Dunaliella or synthetic $\beta$-carotene on the susceptibility of lipoproteins to oxidation.Experimental procedure was as described in the legend to figure 2. The lipoproteins were then oxidized with $10 \mu \mathrm{mol} / \mathrm{l} \mathrm{CuSO}_{4}$, and the oxidation was determined by analysis of the increment in lipoproteinassociated peroxides and the number of malondialdehyde equivalents, as well as by the inhibition of the reduction in trinitrobenzene sulphonic acid reactivity of the lipoproteins.

$* \mathrm{p}<0.01$ vs. control $(\mathrm{n}=3)$.

The effect of $\beta$-carotene on the physicochemical properties of LDL

Analysis of the distribution of the isomers (9-cis and all-trans) in LDL following lipoprotein incubation with $\beta$-carotene from Dunaliella, revealed that both isomers possess the ability to bind to plasma LDL (fig. 4), and their distribution in the lipoprotein was similar to that found in the $\beta$-carotene from Dunaliella. Incubation of LDL with the all-trans isomer $(10 \mathrm{mg} / \mathrm{l})$, but not with the $\beta$-carotene from Dunaliella, was shown to affect the electrophoretic mobility of the lipoprotein with a reduction in its migration from $1.3 \pm 0.2$ to $0.9 \pm 0.1 \mathrm{~cm}$ from the origin $(\mathrm{n}=3)$. 

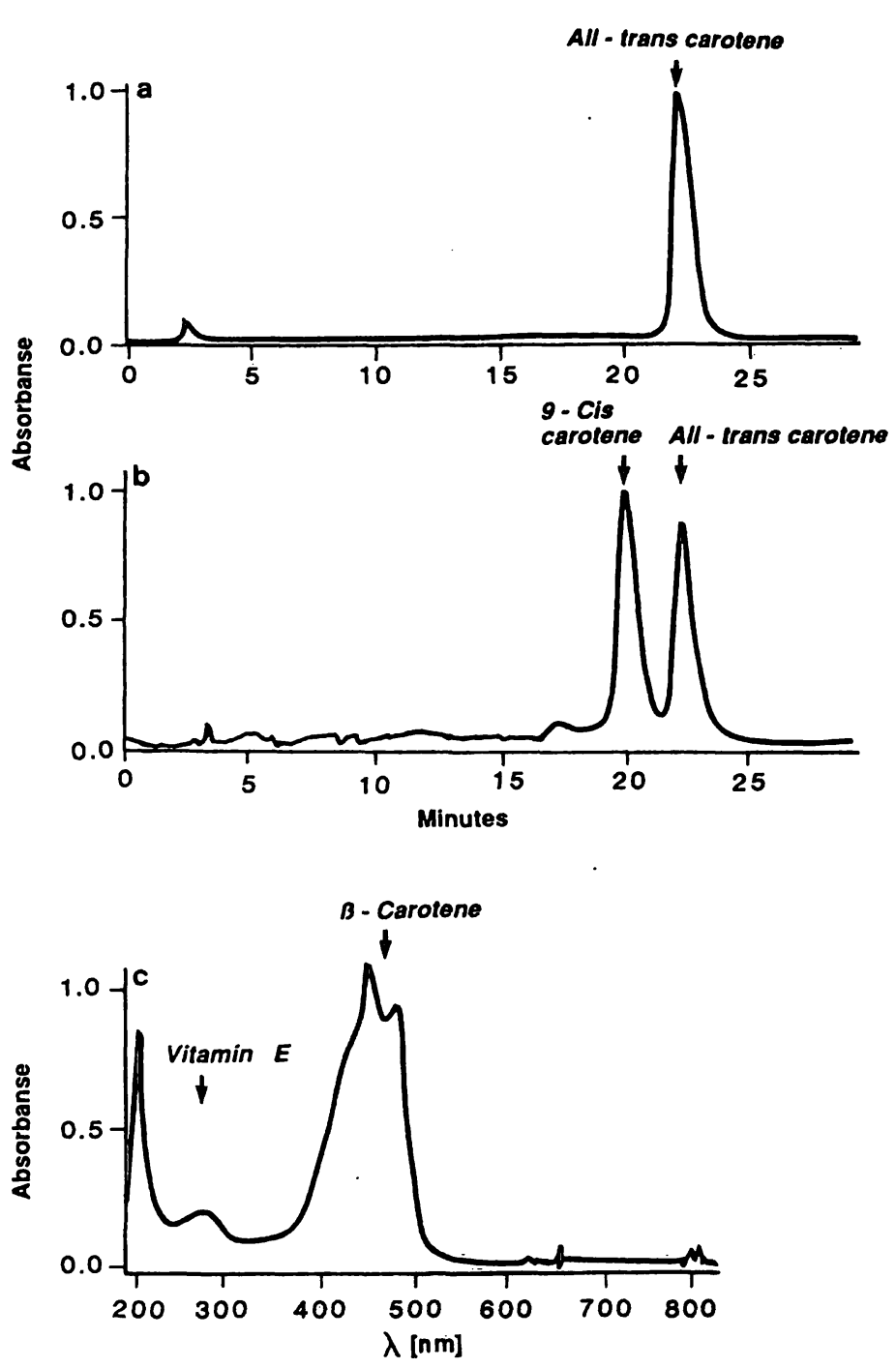

Fig. 4. LDL binding of $\beta$-carotene isomers.

LDL (protein: $1 \mathrm{~g} / \mathrm{l}$ ) was incubated for 2 hours at $37^{\circ} \mathrm{C}$ with $10 \mathrm{mg} / \mathrm{l}$ of the synthetic all-trans isomer of $\beta$ carotene (a) or the 9-cis-enriched Dunaliella $\beta$-carotene (b). The lipoproteins were separated from excess unbound $\beta$-carotene by chromatography on a Sephadex G-100 minicolumn and the LDL-associated isomers were analysed by HPLC (effluent monitored at $450 \mathrm{~nm}$ ). c demonstrates spectrophotometric scanning of the Dunaliella $\beta$-carotene-associated LDL (b).

Trinitrobenzene sulphonic acid reactivities of LDL, incubated with no addition (control), with $\beta$-carotene from Dunaliella, or with the synthetic all-trans isomer were $3.3 \pm 0.2,4.3 \pm 0.3$ or $5.7 \pm 0.4 \mathrm{nmol} / \mathrm{mg} \mathrm{LDL}$ protein, respectively ( $\mathrm{p}<0.01$ vs. control, $\mathrm{n}=3$ ). These values correspond to $30 \%$ and $77 \%$ elevation in the availability of free lysine amino groups on the apolipoprotein B-100 of LDL following its incubation with the Dunaliella and the synthetic $\beta$-carotene, respectively.

The effect of the $\beta$-carotene carrier on its binding to plasma lipoproteins was studied. When dissolved in tetrahydrofuran, the Dunaliella $\beta$-carotene resulted in $33-75 \%$ elevation in lipoprotein-associated $\beta$-caro-
Tab. 1. The effect of the carrier of $\beta$-carotene on its lipoproteinassociation.

\begin{tabular}{lrrr}
\hline \multirow{2}{*}{ Carrier } & \multicolumn{3}{c}{$\beta$-Carotene (nmol/mg protein) } \\
\cline { 2 - 4 } & \multicolumn{1}{c}{ VLDL } & \multicolumn{1}{c}{ LDL } & \multicolumn{1}{c}{ HDL } \\
\hline Tetrahydrofuran & 1.60 & 2.14 & 0.60 \\
Hexane & \pm 0.14 & \pm 0.18 & \pm 0.18 \\
& 1.12 & 1.22 & 0.42 \\
Liposomes & \pm 0.08 & \pm 0.10 & \pm 0.06 \\
& 1.84 & 2.30 & 0.70 \\
& \pm 0.12 & \pm 0.16 & \pm 0.08 \\
\hline
\end{tabular}

$\beta$-Carotene (from Daniella Bardawil) was dissolved in tetrahydrofuran or hexane or encapsulated in phospholipid liposomes. These 3 preparations of $\beta$-carotene $(10 \mathrm{mg} / \mathrm{l}$ final concentration) were incubated with plasma for 2 hours at $37^{\circ} \mathrm{C}$. Plasma lipoproteins were then separated and the $\beta$-carotene content was measured in each fraction. Results are given as mean \pm S.D. $(n=3)$.

tene, compared with $\beta$-carotene dissolved in hexane (tab. 1). A similar effect (to that of tetrahydrofuran) was obtained when $\beta$-carotene was encapsulated in liposomes (tab. 1). The effect of $\beta$-carotene on LDL susceptibility to lipid peroxidation may depend on the location of the $\beta$-carotene in the LDL molecule (i.e. is it bound to the surface lipids or is it incorporated into the core cholesteryl ester moiety of LDL?). In thin layer chromatography, purified $\beta$-carotene migrated to the top of the plate $(13.4 \pm 0.2 \mathrm{~cm}$ from the origin), whereas purified cholesteryl ester migrated $12.5 \pm 0.3 \mathrm{~cm}$ from the origin. The cholesteryl ester spot of LDL (protein $1 \mathrm{~g} / \mathrm{l}$ ) that had been preincubated $\left(2\right.$ hours, $\left.37^{\circ} \mathrm{C}\right)$ with any of the $\beta$-carotene isomers migrated only to $11.2 \pm 0.5 \mathrm{~cm}$ from the origin $(\mathrm{n}=3)$, as visualized by iodine vapor staining. This spot was found to contain $\beta$-carotene (by HPLC analysis), suggesting that $\beta$-carotene binds to the LDL cholesteryl ester moiety.

Vitamin E contents of VLDL, LDL and HDL were as follows: VLDL, $5.85 \pm 0.89 \mathrm{nmol} / \mathrm{mg}$ protein; LDL, $10.80 \pm 0.70 \mathrm{nmol} / \mathrm{mg}$ protein; and HDL, 1.25 $\pm 0.15 \mathrm{nmol} / \mathrm{mg}$ protein, $(\mathrm{n}=3)$. The increased content of $\beta$-carotene in the lipoproteins following their incubation with $\beta$-carotene did not affect the content of vitamin $E$ in all three lipoprotein fractions (data not shown). In vitro oxidation of plasma lipoproteins by incubation at $37^{\circ} \mathrm{C}$ in the presence of $10 \mu \mathrm{mol} / \mathrm{l}$ $\mathrm{CuSO}_{4}$, caused a substantial reduction in the content of lipoprotein-associated $\beta$-carotene in control lipoproteins, as well as in lipoproteins that were preenriched with $\beta$-carotene (tab. 2). The $\beta$-carotene content of these latter oxidized lipoproteins, however, was not decreased to the levels found in control oxidized lipoproteins (tab. 2). 
Tab. 2. Lipoprotein $\beta$-carotene content after in vitro oxidation.

\begin{tabular}{llll}
\hline & \multicolumn{3}{l}{$\beta$-Carotene (nmol/mg protein) } \\
\cline { 2 - 4 } & VLDL & LDL & HDL \\
\hline Control & $0.20 \pm 0.04$ & $0.10 \pm 0.04$ & $0.08 \pm 0.02$ \\
$\begin{array}{l}\beta \text {-Carotene from } \\
\text { Dunaliella }\end{array}$ & $0.30 \pm 0.06$ & $0.16 \pm 0.04$ & $0.10 \pm 0.04$ \\
$\begin{array}{l}\beta \text {-Carotene } \\
\text { synthetic }\end{array}$ & $0.34 \pm 0.06$ & $0.16 \pm 0.06$ & $0.18 \pm 0.04$ \\
\hline
\end{tabular}

Plasma was incubated without or with $\beta$-carotene $(10 \mathrm{mg} / \mathrm{l}$ final concentration) for $2 \mathrm{~h}$ at $37^{\circ} \mathrm{C}$, followed by lipoprotein separation and subsequent in vitro oxidation (following 24 hours of incubation at $37^{\circ} \mathrm{C}$ with $\left.10 \mu \mathrm{mol} / \mathrm{l} \mathrm{CuSO}{ }_{4}\right)$. The content of lipoprotein $\beta$-carotene was then measured. The control values of lipoprotein-associated $\beta$-carotene are considerably higher as demonstrated in figures 1 and 3.

Degradation of $\beta$-carotene-enriched lipoproteins by macrophages

Since $\beta$-carotene enrichement of LDL reduced the lipoprotein susceptibility to lipid peroxidation (in the presence of copper ions), we tested macrophage degradation of the $\beta$-carotene-enriched LDL, following its oxidation ( 24 hours of lipoprotein incubation with $10 \mu \mathrm{mol} / \mathrm{l}$ of $\mathrm{CuSO}_{4}$ ).

J-774A.1 macrophage-like cell line was incubated with oxidized ${ }^{125}$ I-labelled LDL (protein: $25 \mathrm{mg} / \mathrm{l}$; control: LDL or $\beta$-carotene-enriched LDL). Cellular degradation of the lipoproteins that had been oxidized after LDL enrichement with $\beta$-carotene Dunaliella or with

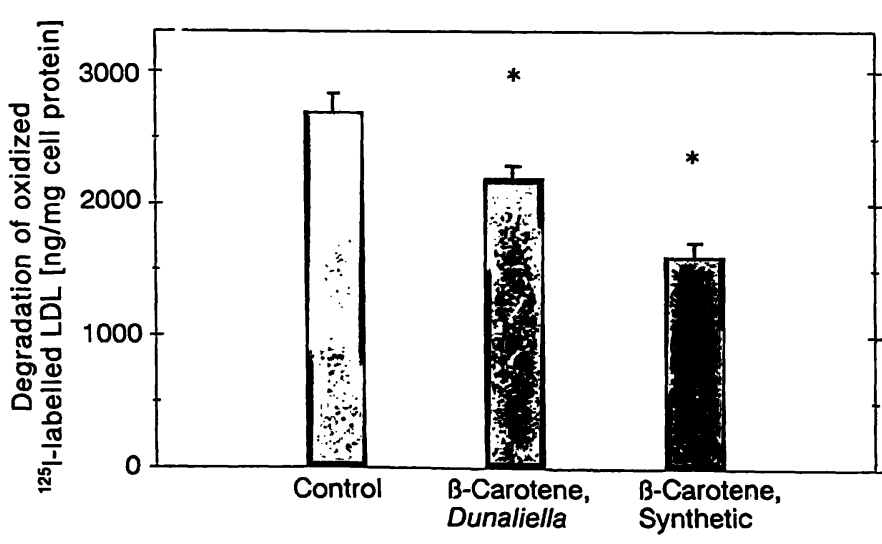

Fig. 5. Macrophage degradation of oxidized LDL and of oxidized $\beta$-carotene-enriched LDL.

${ }^{125} \mathrm{I}$-labelled LDL (protein: $1 \mathrm{~g} / \mathrm{l}$ ) was incubated without (control) or with $10 \mathrm{mg} / \mathrm{l}$ of $\beta$-carotene from Dunaliella or synthetic $\beta$-carotene for 2 hours at $37^{\circ} \mathrm{C}$, followed by lipoprotein separation on a Sephadex G-100 minicolumn.

The lipoproteins were oxidized in the presence of 10 $\mu \mathrm{mol} / 1 \mathrm{CuSO}_{4}$ for 24 hours at $37^{\circ} \mathrm{C}$. J-774A.1 macrophages were then incubated with the oxidized lipoproteins (protein: $25 \mathrm{mg} ; / \mathrm{l}$ ) for 5 hours at $37^{\circ} \mathrm{C}$ and cellular degradation of the oxidized LDLs was determined.

$* \mathrm{p}<0.01$ vs. control $(\mathrm{n}=4)$. synthetic $\beta$-carotene was decreased by $18 \%$ and $40 \%$, respectively, compared with the control oxidized LDL (fig. 5).

When a concentration of ${ }^{125} \mathrm{I}$-labelled oxidized LDL (protein: $10 \mathrm{mg} / \mathrm{l}$ ) was used in the presence of any one of the three types of unlabelled oxidized LDL (protein: $500 \mathrm{~g} / \mathrm{l}$ ), the degradation of the labelled oxidized LDL by J-774A.1 macrophages was decreased by $76 \%-85 \%$. Thus, the oxidized, $\beta$-carotene-enriched LDLs were degraded by the same macrophage receptor as the control oxidized LDL.

\section{Discussion}

The present study demonstrates that both isomers of $\beta$-carotene (the synthetic all-trans isomer and the natural 9-cis isomer) can bind in vitro to plasma lipoproteins. This binding was shown by direct incubation of $\beta$-carotene with the lipoproteins and also by $\beta$ carotene incubation with whole plasma, followed by lipoprotein separation. These findings suggest that plasma constituents do not interfere with the binding of the $\beta$-carotene isomers to the lipoproteins.

Although the 9-cis isomer of $\beta$-carotene binds to the lipoproteins, its inhibitory effect on copper-mediated LDL oxidation was significantly less than that of the all-trans isomer. The susceptibility of lipoproteins to lipid peroxidation is dependent on their content of polyunsaturated fatty acids, as well as on the type and amounts of the antioxidants associated with the lipoproteins $(17,18)$. No effect of $\beta$-carotene could be found on the lipoprotein fatty acid composition. The content of vitamin $\mathrm{E}$, a major antioxidant in plasma lipoproteins $(16-18)$, was also not affected by the binding of $\beta$-carotene to the lipoproteins. Thus, possible changes in lipoprotein-associated vitamin $\mathrm{E}$ could not be responsible for the selective inhibitory effect of $\beta$-carotene isomers on lipoprotein oxidation.

The lower inhibitory effect of $\beta$-carotene from Dunaliella on LDL oxidation compared with the synthetic all-trans isomer, could not be explained simply by the fact that $\beta$-carotene from Dunaliella contains only $70 \%$ of the all-trans isomer, whereas the synthetic isomer is $100 \%$ all-trans, because inhibition by the natural $\beta$-carotene was less than $70 \%$ of that shown by the synthetic $\beta$-carotene. The relationship between inhibition of LDL oxidation and carotenoid content is not necessarily linear. It is also possible that binding of the 9-cis isomer to the lipoprotein has an effect on the interaction of the all-trans isomer with this lipoprotein. This is supported by the finding of reduced electrophoretic mobility and increased availability of 
free lysine amino groups on the LDL apolipoprotein B-100 when the lipoprotein was enriched with the synthetic all-trans isomer but not when it was enriched with the $\beta$-carotene from Dunaliella.

In oxidized LDL, an increased electrophoretic mobility was associated with reduced trinitrobenzene sulphonic acid reactivity as a result of the binding of aldehydes to the free lysine amino groups on the LDL apolipoprotein B-100 (32). Oxidized LDL was shown to be taken up by macrophages at an enhanced rate via the scavenger receptor and not via the LDL receptor (19). In the present study binding of the alltrans isomer (the synthetic $\beta$-carotene), decreased the electrophoretic mobility of LDL, compared with LDL treated with $\beta$-carotene from Dunaliella and control LDL. This could be related to the increased availability of free epsilon amino groups of lysine on the lipoprotein. These groups may become exposed following LDL incubation with the all-trans isomer of $\beta$-carotene as a result of alterations in the lipoprotein configuration.

LDL containing natural $\beta$-carotene was less reactive with trinitrobenzene sulphonic acid than LDL containing synthetic $\beta$-carotene. This may be the result of 9-cis interference with the effect of the all-trans isomer, or it may be simply due to the fact that natural $\beta$-carotene contains less of the all-trans isomer than does the synthetic substance. Oxidized LDL has been shown to be atherogenic, in that it increases the macrophage cholesterol content and forms foam cells $(19-21)$, as well as exerting a cytotoxic effect on cells of the arterial wall and on platelet activation $(37,38)$. Thus, the ability of the all-trans isomer of $\beta$-carotene to inhibit LDL oxidation more than the 9-cis isomer suggests that the all-trans isomer may be more antiatherogenic than the 9-cis isomer. The in vivo situa-

\section{References}

1. Goodwin, T. W. (1984) The Biochemistry of the Carotenoids, vol. 2, 2nd ed., Animals, Chapman and Hall, London.

2. Dimitrov, N. V., Meyer, C., Ullrey, D. E., Chenoweth, W., Mickelakis, A., Malone, W., Boone, C. \& Fink, G. (1988) Bioavailability of $\beta$-carotene in humans. Am. J. Clin. Nutr. 48, 298-304.

3. Micozzi, M. S., Brown, E. D., Taylor, P. R. \& Wolfe, E. (1988) Carotenodermia in men with elevated carotenoid intake from foods and $\beta$-carotene supplements. Am. J. Clin. Nutr. 48, 1061-1064.

4. Schweigert, F. J., Lutterbach, A., Rambeck, W. A. \& Zucker, $H$. (1987) Transport of $\beta$-carotene by the serum lipoproteins in cattle. J. Anim. Physiol. Anim. Nutr. 57, 162.

5. Bjornson, L. K., Kayden, H. J., Mmiller, E. \& Moshell, A. N. (1976) The transport of $\alpha$-tocopherol and $\beta$-carotene in human blood. Blood. J. Lipid Research 17, 343-352. tions, however, may not correspond to that shown in our in vitro studies. Under physiological conditions [for example reduced partial oxygen pressure (11)] the isomers may interact differently with LDL.

The inhibition of LDL oxidation by $\beta$-carotene was associated with a reduction in the cellular degradation of the oxidized LDL by J-774A.1 macrophages. The all-trans isomer of $\beta$-carotene reduced LDL oxidation by $62 \%$, and the cellular degradation of the resulting all-trans-enriched oxidized LDL was inhibited by $40 \%$. In contrast, $\beta$-carotene from Dunaliella inhibited LDL oxidation by only $33 \%$, and the macrophage degradation of the resulting oxidized LDL was decreased by only $18 \%$. Recently it was found (Levy, Ben Amotz, Brook and Aviram, unpublished observation) that following oral administration of the two $\beta$-carotene preparations to humans, the all-trans isomer, but not the 9-cis isomer selectively appeared in plasma. In rats it was previously shown (13) that the 9-cis isomer of $\beta$-carotene preferentially accumulates in the liver. Thus, the different isomers may be metabilized differently. The all-trans isomer may affect the oxidation of plasma lipoproteins, whereas the 9cis isomer may affect more the lipid peroxidation in tissues; as well as cell-mediated oxidation of LDL.

In conclusion, the present study demonstrates that although both isomers of $\beta$-carotene can bind to plasma lipoproteins, the synthetic all-trans isomer possesses greater antioxidant activity towards plasma lipoproteins in vitro.

\section{Acknowledgement}

The authors wish to thank Gertrude Dankner and Rachel Fischler for excellent technical assistance, and Ilana Cohen for preparation of the manuscript.
6. Quintao, E., Witztum, J. L., Parthasarathy, S., Elam, R. \& Steinberg, D. (1989) Role of $\beta$-carotene in the oxidative modification of low density lipoproteins. Arteriosclerosis 9, 758a.

7. Jialal, I., Norkus, E. P., Cristol, L. \& Grundy, S. J. (1991) $\beta$-Carotene inhibits the oxidative modification of low density lipoprotein. Biochim. Biophys. Acta 1086, 134-138:

8. Gaziano, J. M., Manson, J. E., Ridker, P. M., Buring. J. E. \& Hennekens, C. H. (1990) Beta carotene therapy for chronic stable angina. Circulation 82 (Suppl.) III-201.

9. Bertram, J. S., Pung. A., Churley, M., Kappock, I. V. J. J., Wilkins, L. R. \& Cooncy, R. V. (1991) Diverse carotenoids protect against chemically induced neoplastic iranformation. Carcinogencsis $12,671-678$.

10. Burton, G. W. \& Ingold, K. U. (19S4) $\beta$-Carotene: An unusual type of lipid antioxidant. Science $224,569-573$. 
11. Burton, G. W. (1989) Antioxidant action of carotenoids. J. Nutr. 119, 109-111.

12. Ben-Amotz, A., Lers, A. \& Avron, M. (1988) Stereoisomers of $\beta$-carotene in the algae Dunaliella bardawil. Plant Physiol. 86, 1286-1291.

13. Ben-Amotz, A., Mokady, S., Edelstein, S. \& Avron, M. (1989) Bioavailability of a natural isomer mixture as compared with synthetic all-trans- $\beta$-carotene in rats and chicks. J. Nutr. 119, 1013-1019.

14. Krinsky, N. I., Russett, M. D., Handerlman, G. J. \& Snodderly, M. (1990) Structural and geometrical isomers of carotenoids in human plasma. J. Nutr. 120, 1654-1662.

15. Dieber-Roteneder, M., Puhl, H., Waeg, G., Striege, G. \& Esterbauer, H. (1991) Effect of oral supplementation with $D-\alpha$-tocopherol on the vitamin $E$ content of human low density lipoproteins and resistance to oxidation. J. Lipid Res. 32, 1325-1332.

16. Esterbauer, H., Dieber-Rotheneder, M., Striegl, G. \& Waeg, G. (1991) Role of vitamin $E$ in preventing the oxidation of low-density lipoprotein. Am. J. Clin. Nutr. 53, 314S-321S.

17. Esterbauer, H., Striege, G., Puhl, H., Oberveither, S., Rotheneder, M., El-Saadani, M. \& Jurgens, E. (1989) The role of vitamin $E$ and carotenoids in preventing oxidation of low density lipoproteins. Vitamin E: Biochemistry and Health Implications. Ann. N. Y. Acad. Sci. 570, 254-267.

18. Esterbauer, H., Rotheneder, M., Stiriegl, G., Waeg, G., Ashy, A., Sattler, W. \& Jurgens, G. (1989) Vitamin E and other lipophilic antioxidants protect LDL against oxidation. Fat Sci. Technic. 8, 316-324.

19. Steinberg, D., Parthasarathy, S., Carew, T. E., Khoo, J. C. \& Witztum, J. L. (1989) Modification of low density lipoprotein that increase its atherogenicity. N. Engl. J. Med. 320, 915-924.

20. Aviram, M. (1991) Effect of lipoproteins and platelets on macrophages cholesterol metabolism. In. Blood Cell Biochemistry. Vol. 2. Megakarocytes, Platelets, Macrophages and Eosinophils (Harris, J. R., ed.) Plenum Publishing Corporation, New York, NY Chapter 7, pp. 179-208.

21. Brown, M. S. \& Goldstein, J. L. (1983) Lipoprotein metabolism in the macrophage: implications for cholesterol deposition in atherosclerosis. Ann. Rev. Biochem. 52, 223261.

22. Yia-Herttuala, S., Palinski, W., Rosenfeld, M. E., Parthasarathy, S., Carew, T. G., Butler, S., Witztum, J. L. \& Steinberg, D. (1989) Evidence for the presence of oxidatively modified low density lipoprotein in atherosclerotic lesions of rabbit and man. J. Clin. Invest. 84, 1086-1095.

23. Lavy, A., Brook, J. G., Dankner, G., Ben Amotz, A. \& Aviram, M. (1991) Enhanced in vitro oxidation of plasma lipoproteins derived from hypercholesterolemic patients. Metabolism 40, 794-799.

24. Aviram, M. (1992) Low density lipoprotein modification by cholesterol oxidase induces enhanced uptake and cholesterol accumulation in cells. J. Biol. Chem. 267, 218225.
25. Lavy, A., Ben Amotz, A. \& Aviram, M. (1993) Increased susceptibility to lipid peroxidation of chylomicrons and low density lipoprotein in celiac disease. Anal. Nutr. Metabol. (in press).

26. Aviram, M., Dankner, G. \& Brook, J. G. (1990) Platelet secretory products increase LDL oxidation, enhance its uptake by macrophages and reduce its fluidity. Arteriosclerosis $10,559-563$.

27. Fuhrman, B., Brook, J. G. \& Aviram, M. (1991) Activated platelets secrete a protein-like factor that stimulates oxidized LDL receptor acitivty in macrophages. J. Lipid. Rès. 32, 1113-1123.

28. Aviram, M., Williams, K. J., McIntosh, R. A., Carpentier, Y., Tall, A. \& Deckelbaum, R. J. (1989) Intralipid infusion abolishes the ability of human serum to cholesterol-load macrophages. Arteriosclerosis 9, 67-75.

29. Aviram, M. (1983) Plasma lipoprotein separation by discontinuous density gradient ultracentrifugation in hyperlipoproteinemic patients. Biochem. Med. 30, 111-118.

30. Buege, J. A., Aust, S. D. (1978) Microsomal lipid peroxidation. Methods Enymol. 52, 302-310.

31. El-Saadani, M., Esterbauer, H., El-Sayed, M., Goher, M., Nassar, A. Y. \& Jurgens, G. (1989) A spectrophotometric assay for lipid peroxides in serum lipoproteins using a commercially available reagent. J. Lipid. Res. 30, 627631.

32. Steinbrecher, U. P., Witztum, J. L. \& Parthasarathy, S. (1987) Decrease in reactive amino groups during oxidation or endothelial cell modification of LDL. Arteriosclerosis 7, 135-143.

33. Colf, B. \& Veheyden, J. (1967) Electrophoresis and sudan black staining of lipoproteins on gelatinised cellulose acetate. Clin. Chim. Acta 18, 325-330.

34. Lowry, O. H., Rosebrough, N. J., Farr, J. L. (1951) Protein measurement with the Folin phenol reagent. J. Biol. Chem. 193, 265-275.

35. Sukenik, A. \& Carmeli, Y. (1990) Lipid synthesis and fatty acid composition in nannochloropsis SP (Eustigmatophyceae) grown in a light-dark cycle. J. Phycol. 26, 463-469.

36. Chait, A., Bierman, E. L. \& Albers, J. J. (1979) Lowdensity lipoprotein receptor activity in cultured human skin fibroblasts: Mechanism of insulin-induced stimulation. J. Clin. Invest. 64, 1309-1319.

37. Jurgens, G., Hoff, H. F., Chisholm, G. M. \& Esterbauer, H. (1987) Modification of human serum low density lipoproteins by oxidation. Characterization and pathophysiological implications. Chem. Phys. Lipids 45, 315-323.

38. Aviram, M. (1990) Malondialdehyde affects the physicochemical and biological characteristics of oxidized low density lipoproteins. Atherosclerosis 84, 141-143.

Prof. Michael Aviram

Head, Lipid Research Laboratory

Rambam Medical Center

Haifa

Israel 